\title{
CUEVAS DE ENTERRAMIENTO DE LA EDAD DEL BRONCE EN EL PAIS VALENCIANO
}

\author{
ANA FERNÁNDEZ VEGA
}

Las cuevas naturales han sido utilizadas desde los comienzos de la Prehistoria con diferentes finalidades, como nos testimonian los numerosos hallazgos de restos materiales en las mismas, tanto de niveles de habitación como de enterramiento.

Ya con anterioridad nos hemos ocupado del estudio de diferentes tipos de cuevas naturales con restos arqueológicos, primero en un trabajo de conjunto sobre la Edad del Bronce en el País Valenciano (1), y más tarde en otro dedicado a las llamadas cuevas sepulcrales colectivas eneolíticas (2). Teniendo en cuenta que el primer trabajo citado, como obra de conjunto que era, no profundizaba en el análisis exhaustivo de los yacimientos estudiados, y que el segundo se limitaba a las cuevas de enterramiento consideradas eneolíticas, nos pareció de interés completar ambos con el estudio de las cuevas sepulcrales clasificadas como pertenecientes a la Edad del Bronce, dejando las cuevas de habitación de ambos períodos para trabajos posteriores, ya que en el espacio limitado de que disponemos, nos era imposible englobarlas todas.

Comenzaremos por una descripción de las cuevas y de los materiales en ellas depositados, tratando de sintetizar la información y remitiendo al lector para una documentación más amplia sobre las mismas al trabajo de conjunto citado más arriba (3), en el que se recoge toda la información escrita y gráfica, que hemos conseguido localizar sobre éstas.

Posteriormente, y en cuanto al análisis de la información se refiere, seguiremos el mismo esquema utilizado en el estudio de las cuevas eneolíticas (4), tratando los siguientes aspectos:

- localización geográfica de las cuevas,

- características morfológicas de las mismas,

- número de individuos y forma de los enterramientos,

- contexto arqueológico, y

- clasificación cultural y cronológica.

(1) Fernández Vega, A. M.: La Edad del Bronce en el País Valenciano. Tesis Doctoral. Inédita.

(2) Fernández Vega, A. y Galán y Saulnier, C.: "Las denominadas cuevas sepulcrales colectivas eneolíticas del País Valenciano y la Mesetaw. Boletín del M.A.N. (e.p.).

(3) Vid. nota 1.

(4) Vid. nota 2. 


\section{Descripción}

1. Cueva Occidental del Peñón de la Zorra: está situada en la provincia de Alicante, en el término municipal de Villena, y forma parte de un conjunto de hábitat en cerro con enterramientos en cueva. Es una cavidad de unos $2 \mathrm{~ms}$. de boca de entrada y $2 \mathrm{~ms}$. de profundidad, que se abre en las calizas que constituyen el monte, y su planta es casi rectangular con unas dimensiones de $4 \mathrm{~ms}$. por $2 \mathrm{~ms}$., teniendo el acceso hacia el norte y por medio de una galería que se abre a la izquierda de la sala.

Los restos humanos localizados pertenecen a un solo individuo, y los materiales encontrados son: - una punta de flecha de pedúnculo triangular y unos $3,5 \mathrm{cms}$. de longitud, con retoque bifacial y de color melado, en piedra tallada; - dos cuentas de collar de calaita, con forma de tonelete y unas dimensiones de 14 y $10 \mathrm{mms}$. respectivamente; - un dentalium perforado; - un arete de plata de $2 \mathrm{mms}$. de diámetro y $11 \mathrm{mms}$. de, abertura; - fragmentos de un cuenco de pasta negruzca, espatulado, de $10 \mathrm{cms}$. de diámetro de la boca y $5 \mathrm{cms}$. de altura.

Fue descubierta, prospectada y publicada por Soler (5) junto con el poblado y otra cueva existente en la ladera oriental del cerro, y por lo que respecta a su clasificación cultural, el autor la consideró en primer lugar campaniforme (6), al igual que el poblado, en el que aparecía este tipo cerámico, pero posteriormente opina que los enterramientos tal vez deban atribuirse a los inicios de la Edad del Bronce (7), opinión que también mantiene Plá Ballester (8).

2. Cueva Oriental del Peñón de la Zorra: localizada en el mismo cerro que la anterior, es de planta sensiblemente elpisoidal y tenía un semicírculo de piedras a la entrada, estando prácticamente rellena de tierras grises. Sobre un escalón lateral de roca situado junto a la boca de entrada se encontraron restos humanos y fragmentos cerámicos junto con un montón de piedras, y al pie de este escalón estaban los objetos metálicos que luego describiremos, y también, al parecer estaría allí el individuo inhumado (9), aunque apareció revuelto con los restos óseos de zorros, que fueron los que lo destrozaron.

El material recogido está constituido por tres lasquitas y una lasca con restos de cortex, de sílex, en el círculo de piedras de la entrada; cinco vértebras de pez, y los siguientes objetos de metal: - un puñal de lengüeta de $27,5 \mathrm{cms}$. de longitud, $6,8 \mathrm{cms}$. de anchura máxima y $3 \mathrm{mms}$. de espesor; - una punta de Palmela con largo pedúnculo de sección cuadrada, de $16,5 \mathrm{cms}$. de longitud y $2 \mathrm{cms}$. de anchura máxima, y otra muy similar de $15,5 \mathrm{cms}$. de longitud y con el pedúnculo doblado; - un arete de plata formado por una barra de $2 \mathrm{mms}$. de espesor y una abertura de $15 \mathrm{mms}$.

(5) Soler García, J. M.: El Eneolítico en Villena. Serie Arq. n. 7. Univ. de Valencia, 1981.

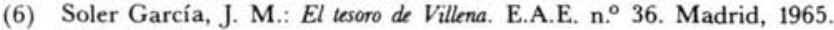

(7) Vid. nota 5.

(8) Plá Ballester, E.: «La covacha Ribera. Cullera (Valencia)». A.P.L. VII, págs. 23-54. Valencia, 1958.

(9) Vid. nota 5 
Los datos sobre su descubrimiento y clasificación cultural son los mismos citados en la anterior, por lo que no creemos necesario repetirlos aquí.

3. Cueva I de Montagut: también situada en la provincia de Alicante, término municipal de Novelda y en un cerro con restos de un poblado y también de otra cueva que carece de restos humanos, solamente conocemos de ella el dato de que está en la ladera sur del cerro y que en ella aparecieron dos costillas y un fémur humano junto con una lámina de piedra tallada, melada, de sección trapezoidal y con doble sierra, y un diente de hoz; una afiladora y molinos de piedra pulimentada, y fragmentos de una vasija de cerámica de borde exvasado con dos mamelones, así como fragmentos indeterminados.

Fue prospectada y publicada (10), clasificándola como perteneciente a la Edad del Bronce con fuerte tradición eneolítica.

4. Cueva dels Fontanars: ubicada en el término municipal de Alcudia des Crespins, provincia de Valencia, está en la ladera de un cerro en el que también se asienta un poblado del mismo nombre. No tenemos sobre ella más datos que los de la existencia de restos humanos y dientes de hoz, aunque de éstos últimos no se especifica con seguridad si son de la cueva o del poblado.

Clasificada también como de la Edad del Bronce y dada a conocer en diferentes noticias (11).

5. Covacha de la Peña del Barreno: situada en el término municipal de Chella, provincia de Valencia, forma parte de un conjunto de covachos que se abren en el Barranco del Lobo y está formada por el amontonamiento de rocas desprendidas de lo alto del barranco, hoy desaparecido. Tenemos, procedentes de ella, y concretamente parece ser que de la cavidad central de la misma (fue volada con explosiones para roturar los campos y después recogido el material), restos de cráneos junto con fragmentos de cerámica lisa, y una punta de flecha de aletas y pedúnculo, una punta de lanza y atípicos de piedra tallada. Estos datos han sido publicados por la Diputación Provincial de Valencia (12) considerándola de la Edad del Bronce.

6. Cueva de la Carrasquilla: localizada en la provincia de Valencia, término municipal de Enguera, carecemos de descripción de la misma, conociendo exclusivamente el dato de que hay restos humanos y hallazgos superficiales de materiales tales como un brazalete de arquero de piedra pulimentada, cerámica lisa y restos de jabalí y ciervo.

También clasificada como de la Edad del Bronce, fue visitada por Vilanova en 1976 y publicada por el mismo autor en 1894 (13), siendo citada posteriormente por otros autores y prospectada de nuevo por Aparicio (14).

(10) Navarro Mederos, J. F.: "Materiales para el estudio de la Edad del Bronce en el Valle Medio del Vinalopó (Alicante)». Lucentum I, págs. 19-70. Univ. de Alicante, 1982.

(11) Diputación Provincial de Valencia: La labor del SIP y su Museo en el pasado año 1971 y 1972 . Valencia, 1973 y 1974.

(12) Fletcher Valls, D. y Aparicio Peŕez, J.: «Exploraciones arqueológicas en el Barranco del Lobo, Chella (Valencia)». Actas del XI C.A.N., págs. 265-270. Zaragoza, 1968.

(13) Vilanova y Piera, J.: Los congresos científicos de Chalons, Berna, Paris, Lisboa y Argel. 1884.

(14) Diputación Provincial de Valencia: La labor del SIP y su Museo en el año 1969. Valencia, 1971. 
7. Coveta Baixa: también en la provincia de Valencia y en término municipal de Estubeny está localizada esta cueva, de la que solamente sabemos que tiene un cuchillo de sílex y cerámica lisa, y que ha sido prospectada y dada a conocer (15) como perteneciente a la Edad del Bronce, posiblemente enterramiento.

8. Cueva Occidental de Salvatierra: en el término municipal de Villena, provincia de Alicante, llamada también Cueva Blanca, está ubicada en la entrada oeste de la vaguada que facilita el paso de una vertiente a otra de la Sierra de la Villa y constituida por una sima con un potente estrato de tierras oscuras y piedras. Hay restos humanos, sin que tengamos más referencias de ellos, junto con cerámica lisa con formas de vasos en "S", mamelones y bordes decorados. Prospectada y publicada por Soler (16) que la considera de la Edad del Bronce.

9. Cova del Castell: profunda sima o grieta con materiales de épocas diversas, localizada en el término municipal de Vallada, en la provincia de Valencia. Aparecieron en ella restos de dos cráneos y "otros", así como cerámica con formas ovoides y fauna indeterminada. También contenía materiales ibéricos, romanos y medievales y se ha considerado como un "posible enterramiento de la Edad del Broncen (17).

10. Cova del Barranc del Castellet: está situada en la provincia de Valencia, término municipal de Carrícola, y ofrece dos niveles anteriores, eneolíticos. Era un pequeño abrigo con amplia entrada, constituido por una cavidad natural poco profunda, de planta rectangular irregular, aproximadamente de unos $5 \mathrm{~ms}$. por 5 ms., que posteriormente fue agrandado. Fue destruido, pero según referencias orales, sobre un posible nivel de habitación y otro de enterramientos eneolíticos, había un enterramiento de inhumación individual con el cadáver en posición decúbito supino sobre una especie de banco hecho de tierra y con un vaso carenado junto a él.

Fue publicado por Plá Ballester (18) que lo clasificó como Bronce II.

11. Alcudia de Veo: en la provincia de Castellón y en el término municipal que da nombre a la cueva, se abre esta cavidad de $12 \mathrm{~ms}$. de profundidad por cinco de anchura máxima y con una altura de 3-4 ms. Contiene dos enterramientos de inhumación, con ajuar, colocados encima de una capa de arcilla recubierta con bloques de piedra. El ajuar es exclusivamente cerámico y está constituido por: - una vasija ovoide de borde exvasado, con un cordón digitado en el cuello, 4 mamelones e incisiones en el borde; - fragmentos de otra vasija ovoide con borde exvasado decorado con incisiones, mamelones y un cordón digitado; - un vaso carenado de base cóncava, bruñido y con un mamelón en la carena; - y fragmentos indeterminados.

Clasificado (19) dentro de la Edad del Bronce con unas fechas en torno al 1400-1300 a. C.

(15) Vid. nota 14.

(16) Vid. nota 5.

(17) Vid. nota 14.

(18) Plá Ballester, E.: «La coveta del Barranc del Castellet». A.P.L. V, págs. 35-64. Valencia, 1954.

(19) Olaria de Gusi, C.: "Cueva de enterramiento del Bronce Valenciano en Alcudia de Veo». C.P.A.C., n. ${ }^{\circ}$ 2, págs. 151-154. Castellón, 1975. 
12. Cova de les Bagases: en término municipal de Bañeres, provincia de Alicante, está situado este abrigo abierto en la caliza de un banco rocoso, en cuya base hay un covacho de $4 \mathrm{~ms}$. de profundidad por $5 \mathrm{~ms}$. de anchura máxima y dos metros de altura, en el que ha hallado un cráneo sin mandíbula y con trepanación en la frente. Los materiales proceden de un cribado de tierras, y son: - un fragmento de percutor sobre canto rodado, y - una ollita de cerámica con un cordón digitado cerca del borde, junto con fragmentos indeterminados.

Explorada y publicada por Aparicio que la considera incluida en la Edad del Bronce (20).

13. Coveta del Monte Picayo: localizada en la provincia de Valencia, término municipal de Sagunto, es una covacha de reducidas dimensiones con la entrada orientada al este. Aún cuando no se han hallado restos humanos en ella, es considerada como un enterramiento, pensando que éstos han desaparecido a causa de la intensa erosión, y se considera que no debieron de ser más de dos individuos debido a las dimensiones de la cueva.

Fue publicada en 1978 (21), y en ella se han recogido los siguientes materiales: - 11 lascas de piedra tallada; - 11 cuentas discoidales negras y 2 verdes, ocho tubulares de rodonita y dos fragmentos de otra de rodonita tubular con doble perforación; - un fragmento de punzón de cobre de sección cuadrada; - y fragmentos de cerámica lisa indeterminados.

Se ha considerado como una de las necrópolis de transición al Bronce Valenciano.

14. Covacha Giner: formando parte de una serie de grietas que ocupan la base de un escarpe vertical, en el término municipal de Cullera (Valencia), aparece la conocida con este nombre que es muy estrecha, de unos $0,75 \mathrm{~ms}$. de anchura, con $1,60 \mathrm{~ms}$. de profundidad y $2,10 \mathrm{~ms}$. de altura, abierta en la caliza y con la boca orientada al sur.

Hay "abundantes" restos humanos (desconocemos el número) y a veces con "signos de quemados", y los materiales recogidos son: - cuentas de collar negras, probablemente de lignito, en número de cincuenta, y de hueso con formas de tonelete, cilíndricas y discoidales así como tres en vértebra de pescado; - cuentas de collar de conchas marinas, caracolillos y dentálidos; -4 punzones fragmentados y dos botones con perforación en "V" de hueso; - dos "laminillas óseas" con perforaciones (¿colgantes?); - y fragmentos de cerámica lisa con formas de cuencos y ollas así como indeterminados.

Considerada también como necrópolis de transición, fue publicada por primera vez en 1971 (22).

Expuestos ya los datos que conocemos sobre las catorce cuevas que nos ocupan, pasamos al análisis de la información con que contamos.

(20) Aparicio Pérez, J.: Las Raices de Bañeres. Serie Arq. n. ${ }^{\circ}$. Univ. de Valencia, 1981.

(21) Lerma, J. V. y Bernabeu, J.: «La coveta del Monte Picayo (Sagunto, Valencia)». A.P.L. XV, págs. 37-46. Valencia, 1978.

(22) Plá Ballester, E.: "Actividades del SIP (1966-70)». A.P.L. XIII. Valencia, 1972 y vid. nota 14 


\section{Localización geográfica}

Sin hacer un análisis exhaustivo de este punto, lo que sería obligado si se tratara de cuevas de habitación, nos limitaremos a decir que hay cinco cuevas en la provincia de Alicante, una en la de Castellón y 8 en la de Valencia, repitiéndose de nuevo, al igual que en las cuevas eneolíticas, el predominio de éstas en la provincia de Valencia, si bien no hay que olvidar que el número de yacimientos del período que nos ocupa, en la Región Valenciana, es en general mucho más abundante en esta provincia, sumando ella sola el doble que las otras dos. Las causas de este desequilibrio pueden ser varias, como exponemos en el trabajo de conjunto anteriormente citado (23).

Por lo que se refiere a comarcas dentro de cada provincia, en Alicante aparecen cuatro de ellas en comarcas regadas por el Vinapoló y la otra en los Valles de Alcoy, quedando por lo tanto claramente limitadas a la zona oeste de la provincia, mientras que en Valencia solamente una de las cuevas está localizada al norte, estando las otras siete en el tercio sur de la provincia, incluyendo la novedad en dos casos, de estar próximas a la costa, hecho que no se da en la de Alicante. Con respecto a Castellón, al tener una solamente, no haremos ningún tipo de análisis pues no nos parece significativo.

\section{Características morfológicas}

Pocos son los datos que poseemos con respecto a este apartado, pues ni siquiera conocemos, en la mayoría de los casos, las dimensiones de estas cuevas, y aún menos, la planta y características de las mismas. En general son de pequeño tamaño, -siendo la mayor de las conocidas la de Alcudia de Veo con unos $60 \mathrm{~m}^{2}-$, al igual que ocurría con las cuevas eneolíticas. Con respecto al tipo de planta, solamente conocemos tres de ellas, dos con tendencia rectangular y una elipsoidal.

Por lo que se refiere a su utilización, nueve de ellas tienen carácter exclusivamente funerario y no están ligadas a ningún asentamiento, al menos de momento, mientras que hay cuatro que aún siendo también solamente funerarias, aparecen directamente relacionadas con asentamientos en cerro; por último, solamente en un caso tenemos una cueva con niveles de hábitat y de enterramiento.

\section{Número de individuos y forma de los enterramientos}

Desconocemos en seis casos el número de individuos inhumados y en uno ni siquiera tenemos restos humanos; las otras siete cuevas nos ofrecen cinco enterramientos individuales y dos dobles. En lo que se refiere a la forma de los mismos, el panorama es aún más sombrío ya que carecemos de información salvo en el caso

Vid. nota 1. 
del Barranc del Castellet, en dónde apareció un inhumado en posición decúbito supino sobre una especie de banco de tierra.

Destacaremos aquí el caso de la Covacha Giner en la que se habla de segundos enterramientos, pero sin más datos, y de signos de quemados. Este ritual funerario que incluiría la cremación total o parcial también se cita en algunas cuevas clasificadas como eneolíticas y en otros tipos de enterramiento, y parece un hecho actualmente comprobado en el SE. (24), pero esporádico y mal documentado en la Región Valenciana, al menos por el momento (25).

\section{Contexto arqueológico}

Solamente en un caso podemos hablar con seguridad de ajuar, o sea de materiales directamente relacionados con el inhumado, y en otro, con ciertas dudas. En las demás cuevas, si bien los materiales aparecen dentro de las mismas, no podemos sin embargo relacionarlos con él o los inhumados ya que desconocemos su posición e incluso en muchos casos su atribución segura a los restos humanos, ya que eran cuevas que estaban muy alteradas. Por último, en algunas ocasiones, ni siquiera sabemos con seguridad que el material proceda de la misma cueva que los restos humanos.

Por todo lo anteriormente expuesto, y porque además este trabajo no puede hacer un detallado estudio de cada uno de los materiales, por razones obvias, nos limitaremos a hacer una breve síntesis de los mismos que nos servirá a la hora de la clasificación cronológica y cultural, al menos como orientación, ya que las características de las cuevas y de los enterramientos - como hemos visto- no nos proporcionan mucha información al respecto.

La piedra tallada está representada por dos puntas de flecha de pedúnculo y aletas, un diente de hoz seguro y varios posiblemente atribuibles a otra cueva (C. dels Fontanars), un cuchillo, lascas y un percutor; en resumen, tenemos objetos de este tipo en ocho de las catorce cuevas.

Solamente en cinco yacimientos aparece piedra pulimentada, siendo en un caso molederas y un alisador, en otro un brazalete de arquero y en tres, cuentas de collar de diferentes formas y materias.

En una sola cueva está representada la industria ósea, en forma de punzones, botones con perforación en "V", cuentas de collar y posibles colgantes, que también aparecen en concha en el mismo yacimiento y en otra cueva.

En metal, tenemos dos aretes de plata en sendas cuevas, y en cobre/bronce, un puñal de lengüeta, dos puntas de Palmela y un fragmento de punzón.

La cerámica es lo más representativo en cuanto a presencia en mayor número de yacimientos y nos ofrece formas tales como cuencos, vasos en "S", ollas, vasos

(24) Muñoz Amilibia, A. M.: “El Eneolítico en el País Valenciano y Murcia”. En Arqueología del País Valenciano: panorama y perspectivas. Univ. de Alicante, 1985.

(25) Idañez Sánchez, J. F.: “Incineración parcial en los enterramientos colectivos eneolíticos del SE. español». Actas de la Mesa Redonda sobre Megalitismo Peninsular, págs. 165 y ss. Madrid, 1986. 
ovoides y carenados. Mamelones, bordes decorados y cordones es todo lo que aparece como elemento decorativo.

\section{Clasificación cultural y cronológica}

Al llegar a este punto, nos encontramos con el aspecto más conflictivo del trabajo, pues no solamente carecemos de fechas absolutas de todos los yacimientos que nos ocupan, sino que además ni la forma de enterramiento, que casi siempre desconocemos, ni los materiales, son claramente determinantes de una etapa cultural concreta. Por lo tanto, cualquier clasificación que hagamos, será un punto de partida o hipótesis de trabajo a confirmar o rebatir cuando tengamos nuevos datos más definitivos, ya sea por nuevas excavaciones, ya sea por publicaciones de datos hasta hoy desconocidos por nosotros.

Así, más que una atribución categórica a una u otra etapa, vamos a considerar todos aquellos indicios que nos inclinen en una u otra dirección, y también aquellos que no contradigan la misma. Es decir, no solamente tendremos en cuenta los elementos que hay a favor de una clasificación determinada, sino también el hecho de que no existan otros que la contradigan.

Partiendo de estos principios, solamente en un caso-Alcudia de Veo-, podemos asegurar que pertenece con claridad a la Edad del Bronce, mientras que en otros cuatro - Cueva de les Bagases (cordones), Cueva I de Montagut (dientes de hoz), Cueva dels Fontaners (aceptando que los dientes de hoz sean del interior de la misma), y Barranc del Castellet II (vaso carenado), aún cuando nos inclinemos por esta posibilidad, la seguridad no es tal como en el caso anterior. Otro yacimiento, la cueva de la Carrasquilla, tiene brazaletes de arquero como material más significativo. Este objeto ha sido considerado con frecuencia como un elemento asociado al vaso campaniforme; sin embargo, Plá Ballester (26) opina que éstos tienen su mayor desarrollo en momentos de Bronce Medio, aunque comiencen a aparecer en el Eneolítico Final, y los resultados de un trabajo ya citado (27) parecen confirmar esta opinión, lo que nos llevaría también a aceptar como válida la clasificación de Edad del Bronce que se le ha dado a este yacimiento.

Con mayores indicios de antigüedad, y por lo tanto, de una posible atribución a un período Eneolítico, tenemos otras cuatro cuevas: Cueva de la Peña del Barreno, Coveta Baixa, Cueva del Monte Picayo y Cueva Occidental del Peñón de la Zorra, y es casi imposible determinar a qué momento podría pertenecer la Cova del Castell, si bien los vasos en "S", que es el único material que ofrece, son más frecuentes en etapas eneolíticas. Por su parte, la Cueva Occidental de Salvatierra, tampoco nos ofrece claros indicios a la hora de su enclave cultural, pero el hecho de que tenga bordes decorados de cerámica nos lleva a pensar más en Edad del Bronce.

(26) Plá Ballester, E.: “Los llamados brazaletes de arquero y el Eneolítico Valenciano». Actas del VIII C.A.N., págs. 216-225. Zaragoza, 1965.

(27) Vid. nota 1. 
Por último, tenemos dos cuevas - Covacha Giner y Cueva Oriental del Peñón de la Zorra- con materiales muy discutidos en lo que a este aspecto se refiere. En la primera de ellas hay dos botones con perforación en "V", y en la segunda un puñal de lengüeta y dos puntas de Palmela, materiales atribuidos en general al denominado "horizonte de transición" (28) y ligados al vaso campaniforme con bastante frecuencia. Aún cuando hemos podido comprobar que estos materiales también aparecen en ocasiones con otros claramente atribuibles a Bronce Medio (29), lo hacen en mucha menor proporción que en etapas eneolíticas, lo que nos llevaría, por tanto, a una etapa anterior a la Edad del Bronce o Bronce Medio. Ahora bien, el problema surge cuando nos planteamos la posibilidad de que estas cuevas puedan ser incluidas o no en ese "horizonte de transición", o mejor, la existencia o no de dicho período, así como las características que se le han atribuido. Y aquí nos enfrentamos con el problema de que no tenemos una coincidencia entre los materiales que se han considerado como definitorios de este período y los yacimientos que se han incluido en el mismo (30), lo que nos lleva a plantear la posibilidad de que si bien es muy posible que exista una larga perduración sin apenas rupturas entre el Eneolítico y la Edad del Bronce en el País Valenciano, pudiendo considerar ésta como un "horizonte de transición", habría que determinar claramente qué materiales y qué yacimientos la conformarían.

Todo lo anteriormente expuesto se refiere a los materiales, y la explicación está en que lo poco que conocemos de la forma de enterramientos y sobre todo el dato de que se trate en estas cuevas de inhumaciones no colectivas, no puede ser utilizado como criterio de clasificación, pues si bien es cierto que el enterramiento colectivo parece mucho más ligado al mundo eneolítico, tenemos casos de materiales claramente atribuibles a Bronce Medio, como es el caso de las alabardas o puñales de remaches, con inhumación colectiva, y aún más, también se da el caso de cuevas con inhumaciones individuales, dobles, o a lo sumo múltiples, que tienen materiales claramente eneolíticos, cuevas que no han sido incluidas en este artículo, ya que no aparecen clasificadas como pertenecientes a la Edad del Bronce.

Si tenemos en cuenta que cuando estudiamos las cuevas consideradas eneolíticas, nos enfrentamos con un problema similar, pero inverso (31) en cuanto a clasificación cultural se refiere, no pudiendo asegurar que muchas de ellas sean realmente eneolíticas, llegamos a la conclusión de que el uso de cuevas naturales en el País Valenciano como lugares de enterramiento debió de ser bastante común y de larga perduración, con variación de número de inhumados y tal vez de formas de ente-

(28) Aparicio Pérez, J.: Las Raices de Bañeres. Arqueología 8. Univ. de Valencia, 1981.

Bernabeu Auban, J.: "Los elementos de adorno en el País Valencianow. P.L.A.V., 14, págs. 109-126. Valencia, 1979.

Lerma Alegría, J. V.: "Los orígenes de la metalurgia en el País Valenciano» A.P.L. XVI, págs. 129-140. Valencia, 1981.

Llobregat Conesa, E. A.: «Del fin del neolítico de cerámicas impresas al comienzo de la Edad del Bronce en la Región Valenciana». P.L.A.V., n. ${ }^{\circ}$ 9, págs. 3-10. Valencia, 1973.

(29) Vid. nota 1, págs. 303 y ss.

(30) Vid. nota 1, págs. 304 y ss.

(31) Vid. nota 2. 
rramiento que desgraciadamente casi desconocemos, y también de que no debió haber cortes radicales durante las etapas eneolítica y Edad del Bronce en éste ni en otros aspectos, como hemos podido observar en el ya tan citado trabajo de conjunto sobre el País Valenciano (32), sino más bien una larga perduración.

Es evidente que las cuevas han sido una de las formas de enterramiento durante la Edad del Bronce en el País Valenciano, y si, como sospechamos, una parte de las que se han venido incluyendo en el grupo de "colectivas eneolíticas", pueden ser realmente de la Edad del Bronce, entendiendo este término como equivalente a Bronce Medio, tal vez tengamos en ellas la respuesta a la interrogante frecuentemente planteada de la escasez de enterramientos frente al abundante número de habitats que se han localizado en esta región como correspondientes a este momento cultural.

El hecho de que la mayoría de estas cuevas sean de pequeño tamaño, nos lleva a plantearnos, como apoyo a nuestra teoría, la posibilidad de que una parte de ellas sean en realidad los famosos "covachos" o "grietas" que sí se han considerado como formas de enterramiento "típicas" de Bronce Medio en el País Valenciano.

En cualquier caso, y para terminar, siempre llegamos a un mismo punto: la absoluta necesidad de excavar yacimientos con las actuales técnicas que nos permitan aclarar todas las dudas sobre cada uno de los aspectos de la cuestión planteados, y confirmen o rebatan las hipótesis de trabajo que aquí hemos expuesto, ya que el hecho de que la mayoría de estos yacimientos hayan sido descubiertos después de ser destruidos, total o parcialmente, hace imposible llegar a conclusiones más definitivas. 